\title{
A model for the domestication of Panicum miliaceum (common, proso or broomcorn millet) in China
}

\author{
Chris J. Stevens ${ }^{1,2}\left(\right.$ D $\cdot$ Gideon Shelach-Lavi $^{3} \cdot$ Hai Zhang ${ }^{1} \cdot$ Mingyu Teng ${ }^{4} \cdot$ Dorian $^{\text {Q. Fuller }}{ }^{2,5,6}$
}

Received: 26 November 2019 / Accepted: 9 October 2020 / Published online: 28 October 2020

(c) The Author(s) 2020

\begin{abstract}
This paper outlines a model for the domestication of Panicum miliaceum (broomcorn millet) in Northern China. Data from 43 archaeological sites indicate a continuous increase in average grain size between 6000 and $3300 \mathrm{BC}$. After this date there is a divergence, with grain size continuing to increase in some populations, while others show no further size increase. The initial increase in grain size is attributed to selection during domestication, while later divergence after $3300 \mathrm{BC}$ is interpreted as resulting from post-domestication selection. Measurements of grains from two archaeological populations of $P$. ruderale, showed grains were longer in length by 3300 вС than the earliest grains of $P$. miliaceum. This suggests this sub-species includes many feral, weedy and/or introgressed forms of $P$. miliaceum and therefore is probably not entirely representative of the true wild ancestor. It is argued that changes from shattering to non-shattering are contemporary with increasing grain size and the commencement of cultivation. The window of $P$. miliaceum domestication is therefore likely to lie between 7000 and 3300 BC. However, it is probable that a lengthy period of millet harvesting and small-scale management preceded its domestication.
\end{abstract}

Keywords Origins of agriculture $\cdot$ Cultivation $\cdot$ Neolithic $\cdot$ Palaeoethnobotany $\cdot$ Shattering $\cdot$ Grain size

\section{Introduction}

Communicated by G. Fiorentino.

Electronic supplementary material The online version of this article (https://doi.org/10.1007/s00334-020-00804-z) contains supplementary material, which is available to authorized users.

Chris J. Stevens

c.stevens@ucl.ac.uk

1 School of Archaeology and Museology, Peking University, No.5 Yiheyuan Road Haidian District, Beijing 100871, China

2 Institute of Archaeology, University of London, 31-34 Gordon Square, London WC1H OPY, UK

3 Department of Asian Studies, The Hebrew University of Jerusalem, Jerusalem, Israel

4 Center for Frontier Archaeology, Jilin University, Changchun 130012, China

5 School of Cultural Heritage, Northwest University, Xi' an, Shaanxi, China

6 Department of Archaeology, Max Planck Institute for the Science of Human History, Kahlaische Strasse 10, 07745 Jena, Germany
Two species of millet were domesticated in China, Panicum miliaceum L. (broomcorn millet) and Setaria italica (L.) P. Beauv. (foxtail millet), and together these formed the staple crops that supported the rise of the northern Chinese dynasties. Archaeobotanical material, preserved mainly by charring, has been used to track the domestication of a number of cereal crops, including rice in China (Fuller et al. 2009) and barley, einkorn and emmer wheat in Western Asia (Fuller et al. 2018). For these crops methodological advancements have made the recognition of morphological domestication processes explicit (e.g. Willcox 2004; Fuller 2007; Tanno and Willcox 2012). Further, through the construction of timelines of morphological change, it has been found that increased grain size in cereals is broadly contemporary with changes in traits relating to seed dispersal, e.g. shattering to non-shattering (Fuller et al. 2014, 2018). However, there has been less archaeobotanical work explicitly addressing the tracking of the domestication processes for either Chinese millet species (for reviews see Hunt et al. 2008; Liu and Chen 2012, pp 82-85). 
Current research often classifies archaeologically recovered grains of Chinese millets taxonomically as their domesticated species, P. miliaceum or S. italica, without considering morphological change during their domestication, with underlying implications that millets were domesticated by $6000 \mathrm{BC}$ (Bettinger et al. 2010; Zhao 2011; Bestel et al. 2014) or even as early as 8000-10000 ВС (Yang et al. 2012, 2015; Wang et al. 2016). However, grains from earlier sites, such as Xinglonggou, have been interpreted as early domesticated forms of $P$. miliaceum, implying that its domestication was still ongoing between 6000-5500 BC (Zhao 2004; Liu et al. 2015; see also Crawford et al. 2016; Bestel et al. 2018), while more recently phytolith studies at Zhuzhai have suggested domestication began around 7000-5000 $\mathrm{BC}$ and continued to as late as 2000-1000 BC (Wang et al. 2018).

Archaeobotanical studies on a large number of crops, looking at changes in grain size and shattering, demonstrate that domestication is a protracted process of evolutionary change, lasting some 2,000 to 3,000 years, driven by unconscious selection (Fuller et al. 2014, 2018; cf. Allaby et al. 2017). While for Chinese millets both rapid (cf. Bettinger et al. 2010) and protracted domestication (cf. Bestel et al. 2014) have been proposed, in the absence of timelines for morphological change such hypotheses are based on an incomplete knowledge of the morphology of pre-domesticated and intermediate semi-domesticated millets, hindering the identification of fully "domesticated" millets. As such we are left with an incomplete understanding of millet domestication, the duration of the process, or its chronological placement within the Chinese Neolithic.

This paper examines just one species, $P$. miliaceum, using grain morphometrics from charred archaeobotanical assemblages in northern China, with the aim of identifying the beginning and end of the domestication process. The study employs established methods that have previously been used to investigate grain size change during domestication for rice, wheat and barley (Fuller et al. 2014, 2017, 2018). These earlier studies have used a combination of grain morphometrics combined with the identification of shattering and non-shattering rachis fragments (Fuller et al. 2009, 2014). However, rachises and spikelet bases of Chinese millets rarely survive charring and hence we are solely reliant on grain morphology as an indicator of millet domestication. As such we also explore the relationship of grain size change to shattering during cereal domestication, looking at proposed processes of selection for shattering and grain size, and whether such synchronicity between changes in grain size and shattering would be expected for all cereals.

\section{The current state of knowledge on millet domestication}

The study of $P$. miliaceum domestication is hampered by the identification of the wild progenitor. One possible candidate, P. ruderale (Kitag) DM Chang (de Wet 1992), may only comprise feral and weedy forms of domesticated P. miliaceum (Hunt et al. 2008), or wild forms that have heavily introgressed with domesticated millet. However, a recent genetic diversity survey suggests that $P$. ruderale likely comprises both descendants of the original wild progenitor and lineages descended from the crop through feralization (Xu et al. 2019). The only other Panicum species in northern China, $P$. bisculcatum, is genetically distinct and so clearly not the wild progenitor (Hunt et al. 2014), further, it is probably taxonomically incorrectly assigned to Panicum given its $\mathrm{C}_{3}$ photosynthesis (Zuloaga et al. 2018). The closest living relatives of $P$. miliaceum are today found in the Americas, and these species likely split from a shared wild ancestor with P. miliaceum some 7 million years ago (Hunt et al. 2014; Zuloaga et al. 2018). The absence of an established wild progenitor means that the separation of pre-domesticated wild grains from domesticated grains on morphological criteria alone is problematic.

The first evidence for $P$. miliaceum comes from five to six Neolithic cultures in Northern China (Liu et al. 2009; Stevens et al. 2016; Stevens and Fuller 2017). The earliest undisputed evidence, associated with direct calibrated radiocarbon dates on charred Panicum grains, is from the following sites: Yuezhuang (5880-5710 BC), a Houli Culture site in Shandong (Crawford et al. 2016); Xinglonggou (5720-5660 BC), Inner Mongolia, associated with the Xinglongwa Culture (Zhao 2011); Zhuzhai (5740-5640 cal BC), a Peiligang Culture site in Henan (Bestel et al. 2018); and Baijia (5710-5550 cal BC) of the Laoguantai Culture in the Wei Valley, Shaanxi (Yang et al. 2016). Grains from Dadiwan, Gansu lack direct AMS dates, but are radiocarbon dated on associated material to ca. 5800-5300 вс (Bettinger et al. 2010). A further site, Cishan, Hebei, has phytolith evidence for P. miliaceum (Lu et al. 2009), but no charred grains have yet been recovered. Radiocarbon dating of the site has produced dates as old as $8000 \mathrm{BC}$ (Lu et al. 2009). However, given these are on an unknown carbon source (not grain as cited) and do not match the charcoal dates of 6000-5500 BC which conform to the general cultural chronology within this region, the older dates are dismissed as unreliable (cf. Zhao 2011; Liu and Chen 2012, p 84; Stevens and Fuller 2017).

Within these early cultures of Northern China (6000-5000 вC), Panicum is usually the dominant millet, with Setaria rare or absent, although during the Yangshao 
period Setaria becomes the dominant millet (Zhao 2004; Barton et al. 2009; Lu et al. 2009; cf. Liu et al. 2009; Crawford et al. 2016; Stevens and Fuller 2017; Bestel et al. 2018; Shelach-Lavi et al. 2019). These cultures also share many aspects in common, including permanent settlement, and tools associated with the management of cereals (Liu and Chen 2012, pp 127-152; Shelach-Lavi 2015, pp 68-95). The most important of these tools for this study are cultivation tools. It should be noted that neither in English nor Chinese is the terminology fixed, and both hoe (Chú 锄) and spade or shovel (Chăn 铲), are used interchangeably. Harvesting tools comprise stylistic serrated or denticulate stone sickles (Lián 镰) in the Peiligang (Fig. 5.12 in Liu and Chen 2012), non-serrated stone Lián in the Houli (Fig. 5.9 in Liu and Chen 2012), and serrated shell sickles in the Laoguantai Culture (Fig. 5.19 in Liu and Chen 2012). Xinglongwa sites have no definitive harvesting tools, although potentially bone knives and hafted microlithic blades could be used for such purposes (Liu and Chen 2012, p 130; cf. Shelach-Lavi and Teng 2013).

A number of sites pre-dating these cultures are known from northern China: Shizitan, Shanxi (11800-9600 вс); Nanzhuangtou, Hebei (9700-8800 BC); and Donghulin (9000-7500 BC) and Zhuannian (8300-7700 BC), both near Beijing. All these sites produced grindstones from which small numbers of starch grains attributed to millets (Setaria and/or Panicum) have been reported (Yang et al. 2012, 2015; Liu et al. 2013). Shizitan also produced charred grains of wild Setaria (Bestel et al. 2014), while Donghulin is described as having "small" but "morphologically domesticated" type grains of both Panicum and Setaria, but these await further study (Zhao 2014). The identification of domesticated type starch should be regarded with caution (cf. Stevens and Fuller 2017), especially in light of the uncertainty about wild progenitors and feralization processes. As such, while these sites provide evidence for the wild harvesting of millet species, including Setaria and Panicum, they do not provide any clear evidence for domestication processes or cultivation (cf. Bestel et al. 2014; Liu et al. 2019).

\section{Data analysis}

In order to analyse grain size change over time, measurements of charred grains of $P$. miliaceum type were collected from 43 sites, spread across 10 provinces, spanning the period from 7000 to 1500 BC (Fig. 1, 2; ESM table S1). For four sites two phases were available providing a total of 47 records, which were divided by site and phase. Seventeen of these records comprise our own measurements of grains, thirteen of which are from the Ying and Luo River Valley Survey, Henan (Fuller and Zhang 2007), two from Shandong and Baligang (Song et al. 2013; Deng et al. 2015) and two from Xinglongwa sites (Fig. 2; Shelach-Lavi et al. 2015, 2019; Teng et al. 2015). Further data were collected from published measurements and photographic records (ESM tables S1-S3).

For many sites, due to the variability in thickness caused by differential responses to charring (cf. Walsh 2017), only width and length measurements are often published, although thickness measurements were collected for some sites. Measurements by the authors were conducted using Leica measuring software on photographs of the dorsal surface: length was measured from a line passing through the middle of the embryo; width measured across the widest point at $90^{\circ}$ to this line; and thickness by turning the grain and photographing the lateral view. Where grains had exploded or puffed they were either discarded, or if undistorted measured to the original grains edge. A midpoint average date for each site phase was calculated from published radiocarbon dates, or where radiocarbon dating was not available an average date from the conventional period range was used instead (ESM Table S1). The data from each site phase (ESM tables S2 and S3) were then plotted, with the date on the $\mathrm{X}$-axis and the mean average measurement (for width, height, thickness and a size index) on the Y-axis. The standard deviation (or estimated standard deviation) was plotted where possible (Figs. 3a, b, c, d).

As Panicum is less common on later sites, and millet grains are rare in general on earlier sites, the number of grains measured per site often comprised all identified grains. On only a few sites were grains numerous enough that sub-samples were measured e.g. Zhuzhai and Xinglonggou (Zhao 2004; Bestel et al. 2018). As such, 21 of the site/phase records have under 10 grains, with only 14 samples having over 20 grains (ESM Table S2). Most records are from single contexts. As such R-square values measuring the closeness of fit to linear/polynomial regression models for average grain measurements against time utilizing various cut-off points for sample size were also calculated.

Sites were grouped into six broad geographical regions. Additionally one larger charred assemblage of $P$. ruderale grain was measured from Tonglin, Shandong, and a smaller one from Yangcun, Henan. Grains of P. ruderale are easily distinguished on differences in general shape from $P$. miliaceum in the same samples (Fig. 2; cf. Fuller and Zhang 2007; Deng et al. 2015), and are plotted separately for comparison with all assemblages. Lastly, to provide an indication of changes in grain shape over time, the length divided by the width for each grain, in each assemblage, was plotted against time. In cases where only the total average width and length for the entire assemblage were available, these figures are used instead and are identifiable by having no standard deviation (Fig. 4a; ESM tables S2 and S3). Finally length was plotted against width for all individual grains, where available, on a single chart grouped by site phase (Fig. 4b). 


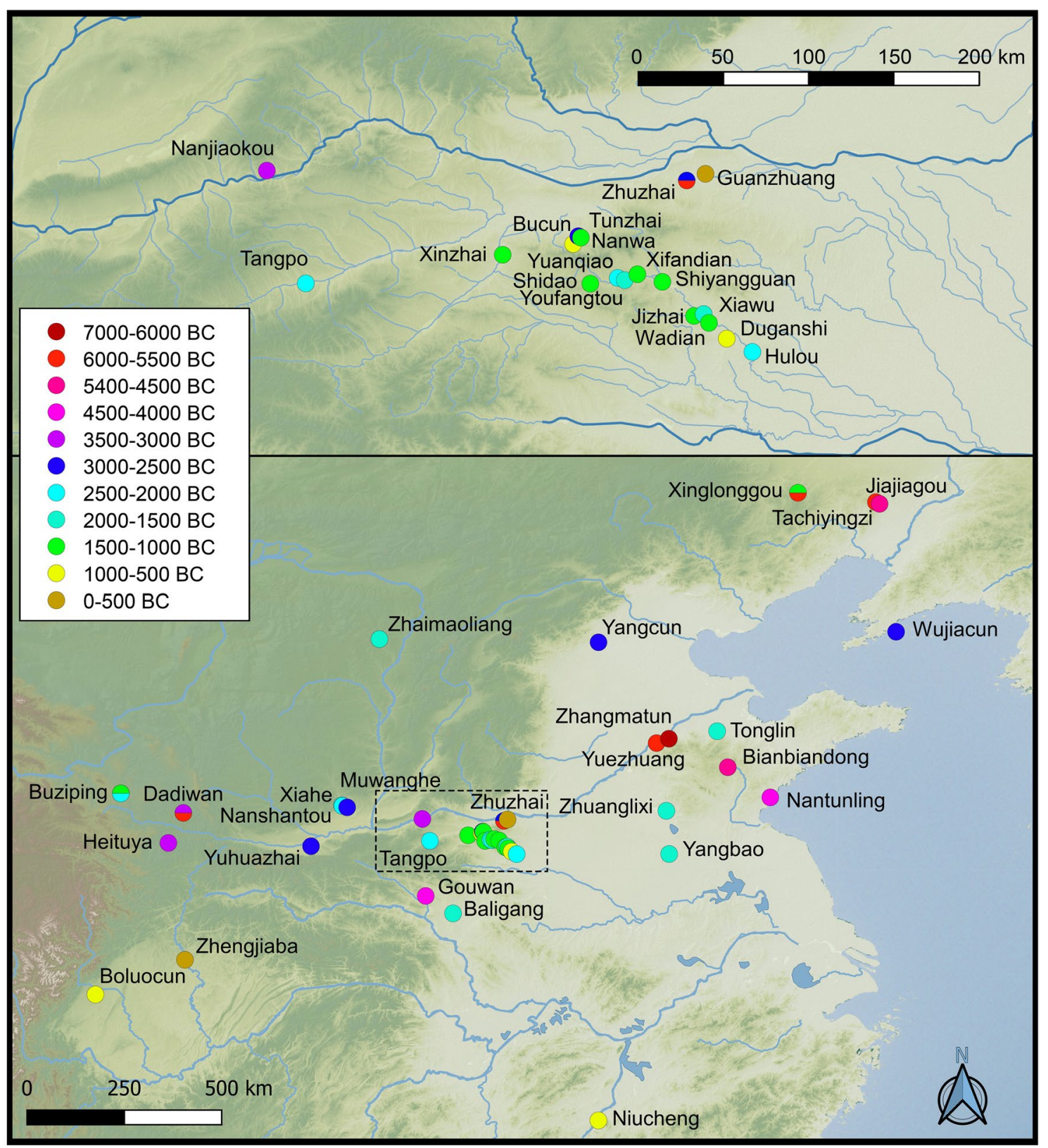

Fig. 1 The location of the 43 sites used within this analysis. The inset shows sites of the Ying and Lou Valley in Henan (for site references see ESM table S1)

Four potential problems with data collection are noted. The first is the presence of immature grains, which are often smaller and notably flatter than mature grains (Fuller and Zhang 2007; Song et al. 2013). Studies have shown that the transition from flatter grains to more mature rounded grains occurs between around 8-15 days after anthesis, with grains becoming wider before they become thicker (Motuzaite-Matuzeviciute et al. 2012). Such grains are often readily identified and were not measured as part of this paper, although they were relatively few, and published photographs rarely include immature seeds. However, immature grains, which had been charred within the later stages of grain maturation, might be less easy to identify, and hence could reduce the mean for any individual site or sample. Furthermore, where other authors' measurements were used this also remains a potential source of noise and outliers.

The second problem is incorrectly dated contexts. While it is unlikely that deposits dated on ceramic typology will be greatly outside an expected age range, it was notable when conducting radiocarbon dating as part of this project that some samples were still up to 500 years from their expected cultural date. 

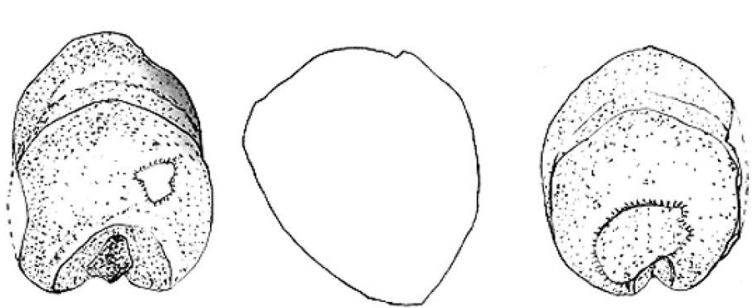

Tonglin, Shandong, Late Neolithic H5000

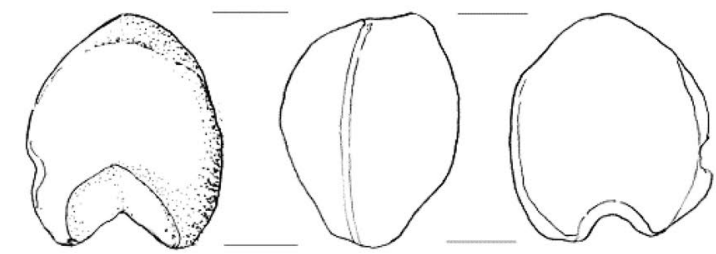

Youfangtou, Henan Late Neolithic, P3H1

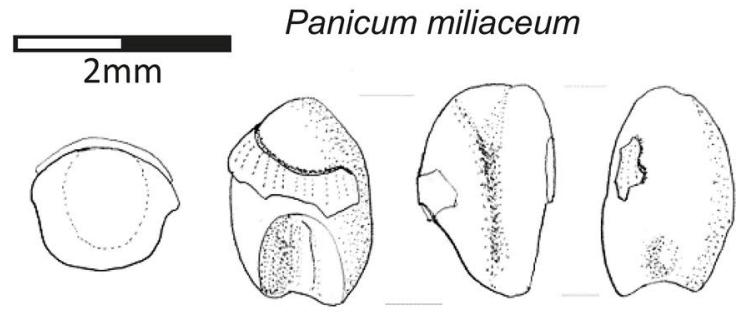

Xiawu, Ying Valley, Henan, $\mathrm{P} 2 \mathrm{H} 1(1)$

Panicum miliaceum ssp. ruderale

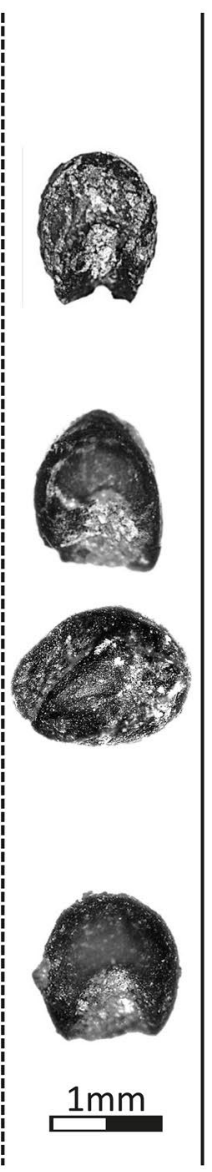

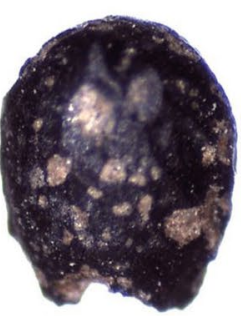

Jiajiagou 12D56

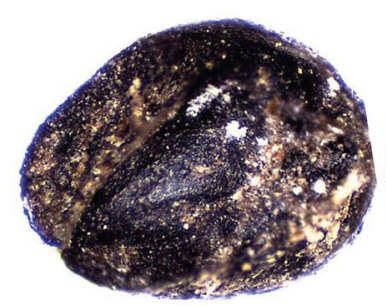

Tachiyingzi 12D16A

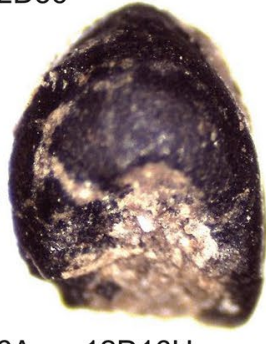

$12 \mathrm{D} 16 \mathrm{H}$

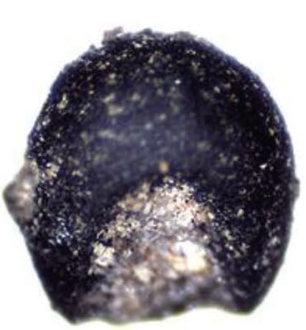

Tachiyingzi 12D16H

Fig. 2 Left: Panicum miliaceum from Tonglin and Youfangtou and P. ruderale from Xiawu, as labelled, scale 2 mm. Right: Panicum miliaceum from Jiajiagou (top) and Tachiyingzi, scale $1 \mathrm{~mm}$. Centre: Grains of Jiajiagou and Tachiyingzi scaled to those on the left

A third issue is the presence of intrusive grains of later date, of which for two sites from Shandong there is a high possibility. At Bianbiandong the authors are cautious that millet grains may be intrusive (Sun et al. 2014), as a radiocarbon date on charcoal yielded a 14th to 15th century AD date, but animal bone from the same deposit was dated to $5220-4940 \mathrm{cal}$ BC. At Zhangmatun six grains of $P$. miliaceum were associated with direct dates on grape pips that dated the context to 7000-6600 cal BC. However, this same context produced two charred grains of wheat, dismissed by the authors as intrusive (Wu et al. 2014), raising the possibility that the millets might also be intrusive. Likewise, reworked grains might also be a problem and, as with intrusive grains, this is more problematic with smaller sample sizes.

Finally, measurements can easily be taken on photographs using the wrong calibration. Such mistakes were noted on published photographs of millets where measurements were also given, and these sites were not used. In a few instances within the authors own data collection such mistakes were noted when calibrations were checked.

\section{Results}

When the site assemblages are plotted by changes in grain dimensions over time, three outliers from Shandong are clearly identifiable (Figs. 3a, b, d). Of these, the results would confirm the grains from Bianbiandong and Zhangmatun, as discussed above, are likely intrusive. The third outlier, Nantuling, produced little material from the samples other than the six measured grains of Panicum and a single charred seed of Nelumbo nucifera. However, it was noted that modern uncharred material was more common than charred material (Chen 2007). Given this information, it is suspected that the charred millet grains from all three sites are intrusive and for this reason they are excluded from further interpretation.

The results from the remaining sites indicate a trend of increasing average grain width across all sites and regions over time. Given that seed size change is likely controlled by multiple genes, and is more complex than domestication traits like non-shattering (Fuller and Allaby 2009; Purugganan and Fuller 2011), we would not expect a perfectly 

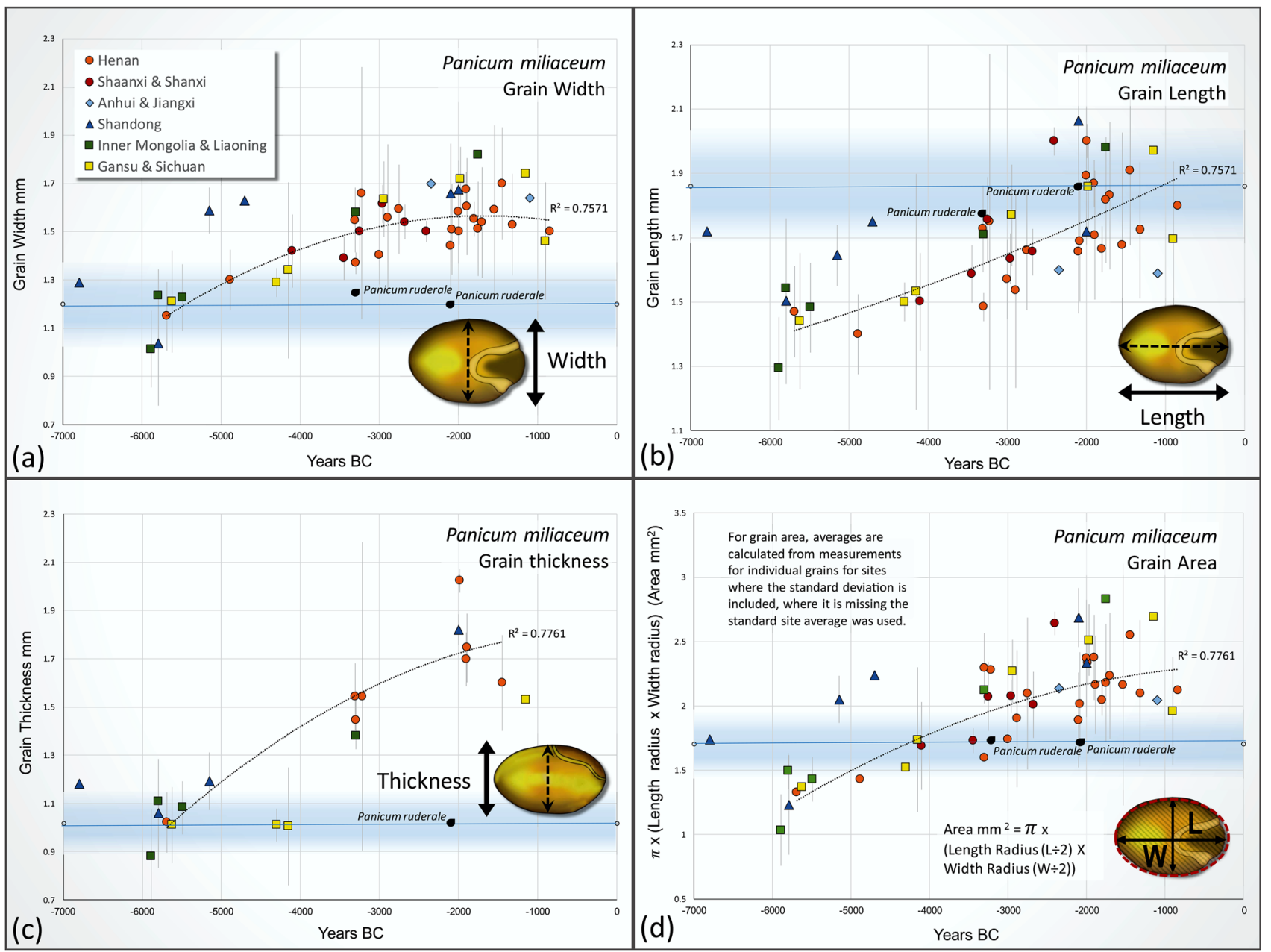

Fig. 3 Charts showing plots for site phase. Y-axis: a grain width; b grain length; $\mathbf{c}$ grain thickness; and $\mathbf{d}$ estimated grain area. $\mathrm{X}$-axis: calibrated years BC. Panicum ruderale is plotted for Yangcun (3305

BC) and Tonglin $(2100 \mathrm{BC})$, the shaded area showing the standard deviation for Tonglin. Note that three early outliers from Shangdong are dismissed as probably intrusive grains

linear relationship through time, especially since even the transition to non-shattering types does not display such linear change (Allaby et al. 2017). As such linear polynomial regression models (using a low order value of 2) were applied and showed a relatively good fit $\left(\mathrm{R}^{2}=0.7571\right)$, and the directionality of change towards increased grain size is clear. Further, these changes are seen to be broadly synchronous across all the geographical regions. Between 6000 and $2000 \mathrm{BC}$ average grain width increased from around $1.1-1.2 \mathrm{~mm}$, levelling off in most populations at $1.5-1.7 \mathrm{~mm}$ after 3300 вс (Fig. 4a). Given larger and smaller sample sizes were present at the beginning and end of the sequence, it is not thought that sample size affected the trend seen. It was notable however that when samples of under 10 grains were removed that the linear polynomial regression model indicated a better fit $\left(\mathrm{R}^{2}=0.8069\right)$, and hence it is likely that at least some variance might be due to small sample size.

A general increase in average grain length over time is also seen, but the regression fit is weak $\left(R^{2}=0.5197\right)$. The three millets from Jiajiagou are shorter on average than those from contemporary sites, which are all around 1.45 to $1.55 \mathrm{~mm}$ long at $5800-5700 \mathrm{BC}$. This stands in clear contrast to sites after $2000 \mathrm{BC}$ where average grain length on most sites is between 1.7 and $2 \mathrm{~mm}$, with small sample size possibly responsible for some outliers. Sites up until 3300 вс do not show a great-deal of change in grain length, but after this date, sites diverge, with an increase in average grain length seen on some sites (Fig. 4b).

Grain thickness, while represented by a smaller dataset, sees a general increase from $0.9-1.1 \mathrm{~mm}$ at $5800-5500$ вС to around $1.7-1.8 \mathrm{~mm}$ at $2000 \mathrm{BC}$ (Fig. 3c). The regression analysis also indicates a stronger fit than seen for length $\left(\mathrm{R}^{2}=0.7423\right)$. As for grain length, it would appear that some sites show further increased grain thickness after 3300 BC, 
Fig. 4 Grain shape: a Grain length divided by width plotted on the Y-Axis against calibrated years BC on the $\mathrm{X}$-axis. b All measured grains plotted by site, with grain width on the $\mathrm{X}$-axis plotted against grain length on the Y-axis. The population of archaeological Panicum ruderale from Tonglin is also plotted and the broad distribution shaded

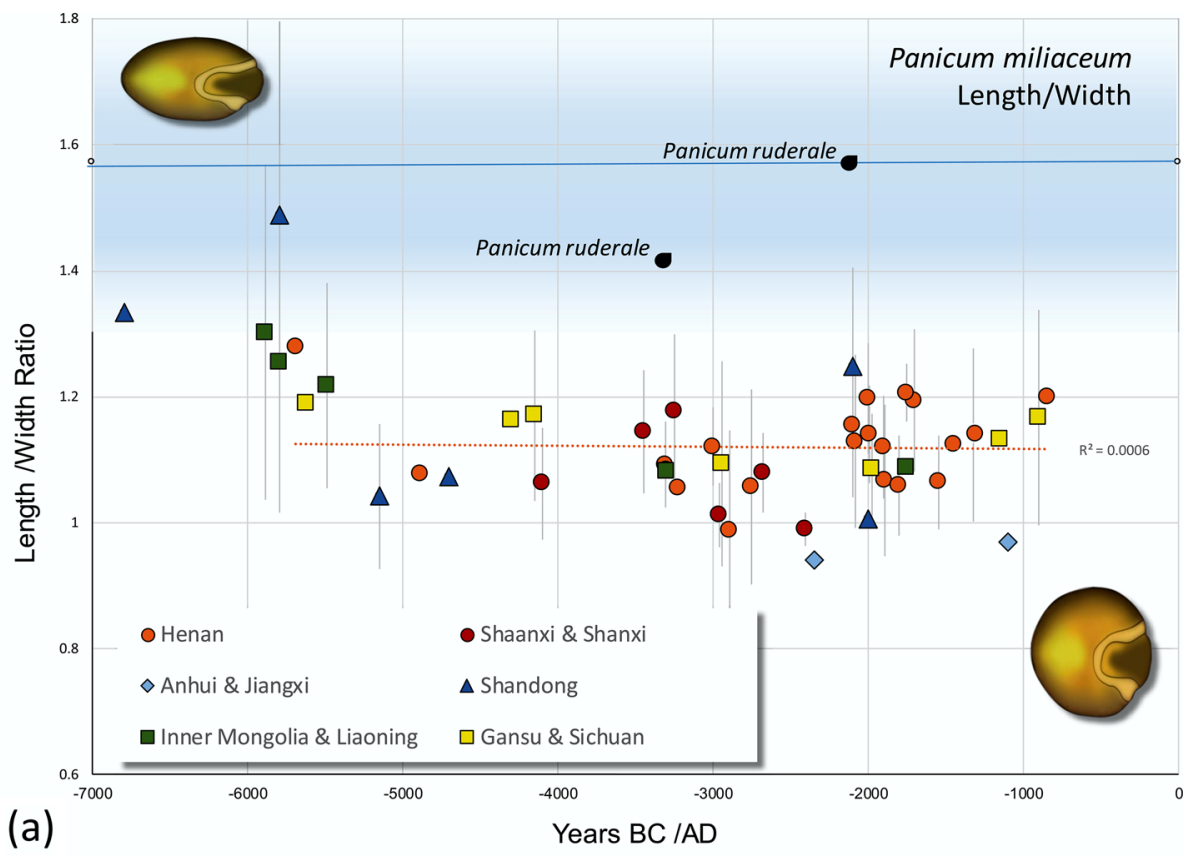

- 5890 BC (Jiajiagou) $\checkmark 5795$ (Yuezhuang) - 5490 BC Tachiyingzi $\times 5150 \mathrm{BC}$ (Bianbiandong) - $4150 \mathrm{BC}$ (Heituya) $\triangle 4100$ BC (Nanjiaokou) ○ 3445 BC (Muwanghe) $\triangle 3305 \mathrm{BC}$ (Yangcun) - $3000 \mathrm{BC}$ (Hulou) - 2960 BC (Nanshantou) - 2945 BC (Buziping) $\triangle 2889$ BC (Yuanqiao) - 2750 BC (Tangpo) - 2400 BC (Zhaimaoliang) $\triangle 2293 \mathrm{BC}$ (Xiahe) $\square 2200 \mathrm{BC}$ (Tonglin) $02100 \mathrm{BC}$ (Baligang) - 2085 BC (Xiawu) - $2000 \mathrm{BC}$ (Youfangtou) $\triangle 1988$ BC (Luyang Basin) ه 1970 BC (Buziping) 1890 BC (Wadian) - 1800 BC (Xinzhai) $\square 1790$ BC Jizhai $\triangle 1750 \mathrm{BC}$ (Xifandian) ○ 1700 BC (Shidao) ○ 1540 BC (Shiyangguan) $\triangle 1323 \mathrm{BC}$ (Duganshi) $\square 900 \mathrm{BC}$ (Zhengjiaba) (b)

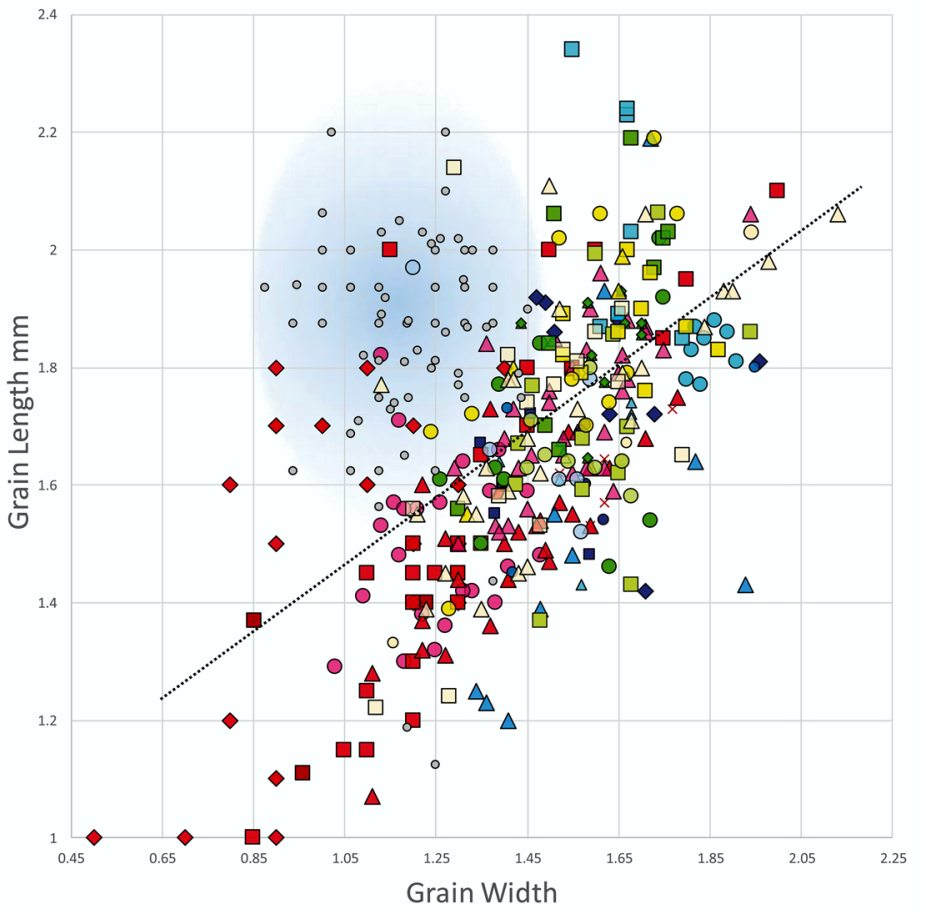

Changes in grain shape are less clear (Figs. 4a, b). There is some separation with all of the earliest sites having grains notably longer than wide, particularly Yuezhuang. However, later sites show a wide range of average values, some being more rounded, others overlapping with earlier sites.

Finally, grains of $P$. ruderale, plotted at 3305 вс (Yangcun) and $2100 \mathrm{BC}$ (Tonglin) appear similar in their average width to the earliest assemblages (5800-5500 BC), but are wider than those from Jiajiagou and Yuezhuang (Fig. 3a). However, the average length of $P$. ruderale is closer to degree of variation seen after $3500 \mathrm{BC}$. 
contemporary domesticated assemblages and on average longer than P. miliaceum grains older than 2000 BC (Fig. 3b). The average grain size of $P$. ruderale is larger or similar to $P$. miliaceum up until 3500-3000 $\mathrm{BC}$, after which average grain size is generally greater than even the largest $P$. ruderale grains (Figs. $3 \mathrm{~d}, 4 \mathrm{~d}$ ). Grains of $P$. ruderale are notably longer on average than they are wide in comparison with $P$. miliaceum grains, with only those of Yuezhuang even approaching such dimensions (see Figs. 4a, b).

\section{Discussion}

The change in grain size can be seen to be strongly correlated to time, and the possibility that factors other than domestication might have influenced increasing grain size were considered unlikely for similar reasons to those given for cereal grain size increase observed in Western Asia (Willcox 2004). That similar increases in grain size over time are seen across wide geographical regions of Northern China would suggest that changes in environment are unlikely to have influenced the observed trend (Fig. 3). Studies of climatic change in Northern China over the Holocene indicate a general warming period from around 9700 to 7500 $\mathrm{BC}$, followed by a warm humid period from $7500-3500 \mathrm{BC}$, with drier cooler phases, and aridification occurring after 3500 вс (Stevens and Fuller 2017), becoming even drier after $2000 \mathrm{BC}$ (Hosner et al. 2016). As such, there is only limited evidence for climatic change (slight drying) during the period over which most grain size increase occurs, with less notable change after 2000 BC when climate was deteriorating more rapidly. Likewise modern studies of Panicum miliaceum suggest that while grain numbers can be reduced under certain environmental conditions grain weight, reflective to some extent of grain size, is relatively stable (Matsuura et al. 2012). Given the extent of climatic and environmental variability, over what is a large geographical region, it is difficult to see how factors, such as climate change or changes in agricultural practices, are likely to have had the uniform effect on size change over time observed. We therefore conclude that size change reflects genetic changes selected for as part of the domestication process.

As such we are left with the issue of fitting these data to a model of $P$. miliaceum domestication. The measured populations of $P$. ruderale are probably not representative of the wild ancestor of $P$. miliaceum, as it seems unlikely that domestication would initially lead to a significant reduction in grain length. Rather these data suggest that populations of $P$. ruderale acquired genes for increased length during the domestication of $P$. miliaceum. These archaeological $P$. ruderale populations can be interpreted as a weedy or feral form, with some adaptations to cultivated environments and/or introgression with domesticated $P$. miliaceum, but lacking those genes responsible for increased grain width and thickness, and presumably non-shattering. It is therefore questionable whether populations of $P$. ruderale still exist that are truly representative of the wild progenitor (cf. Xu et al. 2019). As such, without a baseline for the ancestor of $P$. miliaceum, any attempt to identify grains as cultivated or domesticated by shape or size, without the context of a time series, are likely flawed. Likewise, studies that use $P$. ruderale as representative of the wild progenitor must face similar difficulties, and given the ecological similarities of Setaria viridis (green foxtail), the study of the domestication of $S$. italica should be approached with similar caution. In the absence of evidence for the nature of the true wild progenitors' grains we must consider the possibility that the earliest archaeologically recovered $P$. miliaceum type grains might be broadly representative of the uncultivated wild progenitor. Evidence of cultivation tools in association with many of the earliest specimens (e.g. Shelach-Lavi et al. 2019) would argue that most are likely to have been under cultivation (e.g. pre-domestication cultivation), but to what extent they may have undergone size change, or significantly whether these early populations were predominately shattering or non-shattering, requires further exploration.

Comparative trajectories for other cereals, wheat, barley and rice, where shattering and grain size data are available, measure the start of domestication as that point in time in which the first non-shattering rachises and grain size change occurs in charred assemblages (Fuller 2007; Fuller et al. 2010a, 2014, 2018). The end of the domestication period is seen as that where assemblages are composed predominately of non-shattering rachises, and changes in grain size indicate no further overall increase (Fuller et al. 2014). Once grain size has levelled off, and non-shattering has reached its maximum there is often increased regional variation and divergence in grain size, with some populations getting larger and some smaller (see Fuller et al. 2017). Within these studies the length of the domestication period, from morphologically wild populations to fully domesticated populations is around 2,000-3,000 years, and increased grain size is broadly synchronous with the change from shattering to non-shattering plants.

If $P$. miliaceum grains from the earliest cultures represent partially domesticated forms (cf. Zhao 2004; Liu et al. 2015; Wang et al. 2018), then the most compelling argument by comparison with trajectories for other cereals, is that we are looking at a period from 5900-3300 BC, in which P. miliaceum was still potentially undergoing domestication.

\section{Pathways towards domestication}

\section{Selection for grain size}

In their natural environment, species of Panicum are often adapted to disturbed habitats, particularly relating to flash 
floods in areas with long dry periods. For example, P. capillare, a close relative of $P$. miliaceum, outside of anthropogenic environments inhabits disturbed floodplains and riverbanks (Clements et al. 2004). Likewise, the exploitation of wild Panicum species in the Americas (Nabhan and de Wet 1984) and Australia (Allen 1974) was focused on seasonal floodplains.

The domestication process for plants represents a rebalancing of genetic traits that evolved to be in equilibrium with their natural environment, to one in which genetic traits reach a new equilibrium within an anthropogenic, cultivated environment. The grain size of the wild progenitor of $P$. miliaceum therefore represented a balance between producing numerous smaller grains that maximized the chances of being dispersed to suitable habitats, by wind, river, rain and animals, to producing lower numbers of larger grains that favoured competition after their establishment in suitable environments (cf. Harlan et al. 1973). With cultivation natural grain dispersal is replaced by human action, removing the selection pressure towards smaller seeds, while increasing the role of intraspecific competition during seedling establishment (Harlan et al. 1973; Fuller et al. 2010b).

Two possibilities to explain the selection towards increased grain size during domestication have been suggested (Harlan et al. 1973). The first was that increased grain size results from a competitive advantage where seeds are buried under tillage with larger grains able to push the emergent radicle up to break the soil surface. This explanation has perhaps seen the greater attention (Fuller 2007; Fuller et al. 2010a), but was questioned when experiments showed that it did not provide a competitive advantage in all species, particularly some legumes (Kluyver et al. 2013). The second explanation was that larger seeds have a competitive advantage in that they give rise to larger, stronger seedlings which establish themselves sooner (Harlan et al. 1973).

From the perspective of domestication, the start of cultivation represents a unique environment, in which competing vegetation has been removed and seeds of a single species are sown together, creating a level playing-field in which germinating seeds and their seedlings compete equally for root space, light and nutrients (Fuller and Stevens 2018, 2019). On a microscopic level, small differences in seed size will potentially give those lineages with genetic mutations that increase the plants' average seed size the competitive advantage of establishing faster in the cultivated environment. While between human generations the increase in yield that each minuscule increment in grain size brings is negligible, over the entire domestication period potential yields are increased by some $40 \%$ (Fuller and Stevens 2017), in itself supporting a gradual increased reliance on cereals over time.

\section{Selection for non-shattering}

Changes in grain size, and from shattering to non-shattering plants, have been seen within archaeobotanical assemblages to be broadly simultaneous during cereal domestication (Fuller et al. 2014), but the reasons for this correlation have yet to be fully explained. The causes behind such synchronicity are worth exploring, in part, because changes in shattering behavior might also influence grain size in assemblages through changes in harvesting strategy. But more important, given that rachis fragments for millets are unlikely to be recovered from early assemblages, is to hypothesize whether the selection forces responsible for changes in grain size also play a part in changes from shattering to non-shattering during domestication, and hence whether this temporal correlation is likely to be present across all cereals.

Ethnographic studies demonstrate a number of harvesting and processing methods employed in the exploitation of wild and semi-wild populations of Panicum for its grain in Australia and the Americas, including uprooting, cutting with a stone knife, and hand-stripping into baskets (Gregory 1887, p 132; Allen 1974; de Wet 1975; Nabhan and de Wet 1984; Smith 2013, p 331). For most wild cereals, the ripening of ears between plants, on individual plants, and even between grains on the panicle is asynchronous (Hillman and Davies 1990). As such, in order to obtain a sizeable harvest, in many cases wild Panicum stands were harvested green (e.g. Parker 1905, pp 1-8; Allen 1972, p 313), which was also noted in Africa where wild grasses are green-harvested, including P. laetum (Harlan 1989). Further, experimentation has shown that green harvesting is a more effective method of harvesting wild grasses for grain, even with a sickle (Lu 1998; Willcox 2007). As such green harvesting is seen as an important step towards domestication (Fuller 2007; Fuller and Qin 2008; Fuller et al. 2010b).

Green harvesting works due to the ability of grains that have reached a certain stage of post-anthesis development to continue ripening even when deprived of external nourishment, a trait shared among many grasses (cf. Hillman and Davies 1990). As the abscission layer between the spikelet and rachis, responsible for natural dispersal, forms before or during flowering it will often disarticulate ripened spikelets from the rachis and panicle, even after the panicle has been separated from the plant.

After harvest naturally shattering spikelets are disarticulated from the plant, often after a period of drying, by trampling (Allen 1974), beating (Gregory 1887; Allen 1972, p 77; Nabhan and de Wet 1984; Gerritsen 2014), burning (Parker [Langloh Parker] K, 1905, p 118; Allen 1972, p 76), shaking (de Wet 1975) or hand-stripping (Nabhan and de Wet 1984; Smith 2013, p 331). While some methods, particularly shaking, may be less effective at separating nonshattering grain from the plant, it is worth noting that even 
domesticated, non-shattering $P$. miliaceum panicles loose seed when fully dried (Martin 1929), and hence require less force to separate them than seen for other cereals. Therefore, with many of these methods, grain from non-shattering plants will have a chance of being sown with spikelets of shattering plants (Hillman and Davies 1990).

Outside of cultivation, grasses with non-shattering mutations are generally selected against, as their spikelets have less chance of being dispersed away from the parent and/or of being incorporated into the soil. As such, in wild grass populations non-shattering mutants are rare. With green harvesting, occasional non-shattering plants will be harvested and potentially sown, alongside shattering plants. While this argument provides a low level of selection for non-shattering plants, it is not adequate to explain the shift from shattering to non-shattering that domestication requires. Non-shattering morphotypes might no longer be selected against, but they have no apparent advantage over shattering types, given both morphotypes are potentially resown (cf. Hillman and Davies 1990).

For P. miliaceum, as for many grasses, both weedy and domesticated varieties ripen from the tip of the inflorescence or panicle to its base, so that the tip is shedding grain while the basal spikelets are still green and ripening (Martin 1929; Cavers and Kane 2016), something that is also recorded for domesticated rice (Hay and Spanswick 2006). This aspect of non-synchronous ripening may provide part of the explanation for the selection for non-shattering, as grain from shattering plants will be dispersed naturally prior to green harvesting which is generally timed to maximize yield just after the first spikelets come into maturity (cf. Hillman and Davies 1990; Fig. 9 in Fuller 2007).

Where seed is re-sown from natural stands, but with no cultivation (cf. Nabhan and de Wet 1984; Gerritsen 2014), the stand is replenished by a combination of seed lost prior to harvesting, by plants that escape harvesting, and sown harvested grain. Under this scenario grain from non-shattering mutants has a chance of being sown, and therefore being maintained within wild stands in small numbers. This scenario potentially allows for the small accumulation of nonshattering mutants in wild stands, accounting for the long tails of minuscule selection coefficients for non-shattering prior to the main domestication episode seen for wheat, barley and rice (Allaby et al. 2017).

Within this scenario the issue is that there is no selection against shattering plants in relation to non-shattering mutants; as every spikelet from a shattering plant has an equal chance of producing the next generation by virtue of being either sown or dispersed prior to harvesting. This was a problem discussed at some length by Hillman and Davies (1990), but they did not consider the potential role of tillage. With cultivation naturally dispersed grain from wild-type shattering plants that germinate before tillage will potentially be destroyed, assuming that tillage and weeding are conducted just prior to sowing after the first rains (cf. Forbes 1904, p 119; Bray 1984, p 245). This scenario would be further strengthened should small cultivated stands be established nearer settlements away from replenishment by natural stands (cf. Palmer 1871, p 419).

Under cultivation, non-shattering domesticated-type mutants whose grain was selected for sowing would then begin to gain a small selective advantage over their shattering wild-type relatives. This would occur as seedlings of wild-type shattering plants, that germinate from grain shed before green-harvesting, are selected against by tillage, while grain from panicles of non-shattering domesticated type plants will remain intact to be harvested and potentially sown (cf. Harlan et al. 1973). Therefore, the probability of any given spikelet from a single panicle of a non-shattering plant becoming harvested, sown and re-establishing that lineage represents a selective advantage over any given spikelet from the panicle of a shattering wild-type progenitor. This selective advantage would be very small, especially given that non-shattering mutants would be much rarer to begin with, but would account for the protracted period of domestication seen.

Hence, a positive selection for domestication traits, such as increased grain size and non-shattering, at the expense of those associated with wild progenitors, would be reliant on a continuously repeated cycle that includes all elements of cultivation; clearance, tillage, harvesting, post-harvest separation of spikelets, and sowing. Taken together this hypothetical model of selection can account for why certain domestication traits, such as increased grain size and nonshattering, appear broadly contemporary in those cereals studied to date (Fuller et al. 2014, 2018). It is also possible, given that smaller green immature grains are more likely to be harvested with green harvesting, that prior to selection for non-shattering plants, smaller immature grains might be more prevalent in earlier assemblages (as has been argued for rice: Fuller 2007).

\section{Conclusion}

This analysis argues that the domestication of $P$. miliaceum was still ongoing between 6000 and 3300 BC, with continuous cultivation unlikely to have commenced before $6500 \mathrm{BC}$, and fully domesticated forms appearing between 4000 and 3300 BC. This is largely in agreement with a phytolith study conducted by Wang et al. (2018). However, the later part of their domestication episode, which they see continuing to 2000-1000 BC, we would attribute to post-domestication diversification. This diversification could be attributed to the appearance of larger grained varieties alongside populations whose grain size is still similar to populations dating to 3300 
BC. However, such diversification might also be associated with environmental conditions, such as the expansion of cultivation into marginal areas with less suitable soils, or to the less stable climate conditions that existed after 2000 BC.

The dating of the domestication episode, between 6500-3300 BC, does not exclude a protracted period of precultivation exploitation of millets and other grasses (cf. Yang et al. 2012, 2015; Bestel et al. 2014; Liu 2015; Wang et al. 2016), including periodic sowing, that potentially maintained a low-level of selection for non-shattering mutants, as suggested for other cereals (Allaby et al. 2017). The widespread evidence for the cultivation of early forms of $P$. miliaceum across several regional cultures prior to 5500 BC supports a multi-centric model for the origins of early millet cultivation that was likely born from shared millet gathering traditions across Northern China from the start of the Holocene.

The proposed model for millet domestication closely matches, in both timing and nature, that seen for rice in the lower Yangtze, in which the earliest stages of domestication are accompanied by evidence for increasing sedentism and settlement complexity (7000-5000 BC), alongside continued exploitation of wild foods that are still highly represented within these earliest cultures in comparison to later periods (Fuller and Qin 2010; Stevens and Fuller 2017; cf. Zhao 2004; Wang et al. 2016; Bestel et al. 2018; Shelach-Lavi et al. 2019; and in Western Asia, Maeda et al. 2016).

In Western Asia it appears that a preference for sickles emerged after non-shattering had already become prevalent, therefore reflecting an increasing reliance on cereals (Maeda et al. 2016). In northern China while sickles are present from the start of cultivation, a transition to new types of harvesting tools is evident during the Yangshao period with the appearance of ceramic harvesting knives and later stone rectangular or lunate harvesting knives (Shídāo 石刀). Such a change may be correlated with an increased dominance of non-shattering plants. However, while such knives seem suited to non-shattering panicles, the panicles of domesticated broomcorn millet even today still ripen asynchronously and shatter to some extent in drier conditions, and hence are still harvested partially green (Martin 1929, p 10; Cavers and Kane 2016). Bray (1984, pp 323-333) has further extolled the virtue of such knives in harvesting millets as panicles also ripen asynchronously between plants, hence their use potentially facilitates a second harvest.

Acknowledgements The research undertaken within this paper was supported by a European Research Council grant "Comparative Pathways to Agriculture" (ComPAg, no. 323842) and work in China was facilitated through ICCHA (中国文化遗产保护与考古学硎究国际 中心; International Centre for Chinese Heritage and Archaeology). The funding for the fieldwork in Liaoning was provided by the Israel Science Foundation (Grants no. 501/11 and 728/17 to G.S), and the National Geographic Society (Grant no. 8 614-09 to G.S.) and a large portion of the samples were floated by Wang Huan from these sites. Material collected in Ying and Luo Valley Survey in Henan was undertaken with the assistance of the Henan Provincial Institute of Cultural Heritage and Archaeology, along with the Luoyang Institute of Cultural Heritage and Archaeology. Some of the measurements on archaeological $P$. ruderale from Tonglin were taken by Mukund Kajale when he was a visiting scholar at UCL, and we are grateful for the use of these data.

Open Access This article is licensed under a Creative Commons Attribution 4.0 International License, which permits use, sharing, adaptation, distribution and reproduction in any medium or format, as long as you give appropriate credit to the original author(s) and the source, provide a link to the Creative Commons licence, and indicate if changes were made. The images or other third party material in this article are included in the article's Creative Commons licence, unless indicated otherwise in a credit line to the material. If material is not included in the article's Creative Commons licence and your intended use is not permitted by statutory regulation or exceeds the permitted use, you will need to obtain permission directly from the copyright holder. To view a copy of this licence, visit http://creativecommons.org/licenses/by/4.0/.

\section{References}

Allaby RG, Stevens CJ, Lucas L, Maeda O, Fuller DQ (2017) Geographic mosaics and changing rates of cereal domestication. Philos Trans R Soc London B Biol Sci 372:20160429

Allen H (1972) Where the crow flies backwards: Man and Land in the Darling Basin. Unpublished PhD thesis, Australian National University, Canberra

Allen H (1974) The Bagundji of the Darling Basin: Cereal gatherers in an uncertain environment. World Archaeol 5:309-322

Barton L, Newsome SD, Chen F-H, Wang H, Guilderson TP, Bettinger RL (2009) Agricultural origins and the isotopic identity of domestication in northern China. Proc Natl Acad Sci USA 106(14):5523-5528

Bestel S, Crawford GW, Liu L et al (2014) The evolution of millet domestication, Middle Yellow River Region, North China: Evidence from charred seeds at the late Upper Paleolithic Shizitan Locality 9 site. Holocene 24:261-265

Bestel S, Bao YJ, Zhong H, Chen XC, Liu L (2018) Wild plant use and multi-cropping at the early Neolithic Zhuzhai site in the middle Yellow River region, China. Holocene 28:195-207

Bettinger RL, Barton L, Morgan C (2010) The origins of food production in North China: A different kind of agricultural revolution. Evol Anthropol 19:9-21

Bray F (1984) Science and Civilisation in Ancient China, Vol 6: Biology and Biological Technology, Part 2: Agriculture. Cambridge University Press, Cambridge

Cavers PB, Kane M (2016) The Biology of Canadian Weeds: 155. Panicum miliaceum L. Can J Plant Sci 96:939-988

Chen XX (2007) Analysis of flotation soil sample results from two sites in Rizhao. Nanfangwenwu (Cultural Relics of southern China) 2007:92-94 ((in Chinese))

Clements DR, DiTommaso A, Darbyshire SJ, Cavers PB, Sartonov AD (2004) The biology of Canadian weeds: 127. Panicum capillare L. Can J Plant Sci 84:327-341

Crawford GW, Chen XX, Luan FS, Wang JH (2016) People and plant interaction at the Houli Culture Yuezhuang site in Shandong Province, China. Holocene 26:1594-1604

De Wet JMJ (1975) Evolutionary dynamics of cereal domestication. Bull Torrey Bot Club 102:307-312 
De Wet JMJ (1992) The three phases of cereal domestication. In: Chapman GP (ed) Grass evolution and domestication. Cambridge University Press, Cambridge, pp 176-198

Deng ZH, Qing L, Gao Y et al (2015) From early domesticated rice of the Middle Yangtze basin to millet, rice and wheat agriculture: Archaeobotanical macro-remains from Baligang, Nanyang basin, Central China (6700-500bc). PLoS ONE 10:e0139885

Forbes RH (1904) The Colorado River of the West. The University of the Arizona Monthly 6. University of Arizona Press, Tucson, pp 119-126

Fuller DQ (2007) Contrasting patterns in crop domestication and domestication rates: recent archaeobotanical insights from the old world. Ann Bot 100:903-924

Fuller DQ, Allaby R (2009) Seed dispersal and crop domestication: shattering, germination and seasonality in evolution under cultivation. Ann Plant Rev 38:238-295

Fuller DQ, Qin L (2008) Immature rice and its archaeobotanical recognition: a reply to Pan. Antiquity $82(316)$. https://antiquity. ac.uk/ProjGall/fuller2

Fuller DQ, Qin L (2010) Declining oaks, increasing artistry, and cultivating rice: The environmental and social context of the emergence of farming in the Lower Yangtze Region. Environ Archaeol 15:139-159

Fuller D, Stevens CJ (2017) Open for competition: domesticates, parasitic domesticoids and the agricultural niche. Archaeol Int 20:110-121

Fuller DQ, Stevens CJ (2018) The making of the botanical battle ground: domestication and the origins of the World's weed floras. In: Lightfoot E, Liu XY, Fuller DQ (eds) Far from the Hearth: Essays in Honour of Martin K. Jones, McDonald Institute of Archaeology, Cambridge, pp 9-21

Fuller DQ, Stevens CJ (2019) Between domestication and civilization: the role of agriculture and arboriculture in the emergence of the first urban societies. Veget Hist Archaeobot 28:263-282

Fuller DQ, Zhang H (2007) A preliminary report of the survey archaeobotany of the Upper Ying Valley (Henan Province). In: School of Archaeology and Museology, Peking University \& Henan Provincial Institute of Cultural Relics and Archaeology (ed) Archaeological Discovery and Research at the Wangchenggang Site, Dengfeng (2002-2005). Da xiang chu ban she, Zhengzhou, pp 916-958 (in English and Chinese)

Fuller DQ, Qin L, Zheng YF et al (2009) The domestication process and domestication rate in rice: Spikelet bases from the lower Yangtze. Science 323:1607-1610

Fuller DQ, Allaby RG, Stevens CJ (2010) Domestication as innovation: the entanglement of techniques, technology and chance in the domestication of cereal crops. World Archaeol 42:13-28

Fuller DQ, Sato YI, Castillo C et al (2010) Consilience of genetics and archaeobotany in the entangled history of rice. Archaeol Anthropol Sci 2:115-131

Fuller DQ, Denham T, Arroyo-Kalin M et al (2014) Convergent evolution and parallelism in plant domestication revealed by an expanding archaeological record. Proc Natl Acad Sci 111:6147-6152

Fuller DQ, Colledge S, Murphy C, Stevens C (2017) Sizing up cereal variation: patterns in grain evolution revealed in chronological and geographical comparisons. In: Fernández Eraso J, Mujika Alustiza JA, Arrizabalaga Valbuena A, García Díez M (eds) Miscelánea en homenaje a Lydia Zapata Peña (1965-2015). Universidad Del País Vasco, Bilbao, pp 131-149

Fuller D, Lucas L, Gonzalez Carretero L, Stevens CJ (2018) From intermediate economies to agriculture: trends in wild food use, domestication and cultivation among early villages in Southwest Asia. Paléorient 44:61-76
Gerritsen R (2014) Australia and the Origins of Agriculture. In: Smith C (ed) Encyclopedia of Global Archaeology. Springer, New York, pp 591-600

Gregory AC (1887) Memoranda on the Australian Aborigines. J Anthropol Inst Great Brit Ireland 16:131-133

Harlan JR (1989) Wild grass-seed harvesting in the Sahara and subSahara of Africa. In: Harris DR, Hillman GC (eds) Foraging and Farming: the Evolution of Plant Exploitation. Unwin Hyman, London, pp 79-98

Harlan JR, de Wet JMJ, Price EG (1973) Comparative evolution of cereals. Evolution 27:311-325

Hay JO, Spanswick RM (2006) Computational analysis of rice (Oryza sativa L.) panicle topology and ripening. Seed Sci Res $16: 243-250$

Hillman GC, Davies MS (1990) Measured domestication rates in wild wheats and barley under primitive cultivation, and their archaeological implications. J World Prehist 4:157-222

Hosner D, Wagner M, Tarasov PE, Chen XC, Leipe C (2016) Spatiotemporal distribution patterns of archaeological sites in China during the Neolithic and Bronze Age: An overview. Holocene 26:1576-1593

Hunt HV, Vander Linden M, Liu X et al (2008) Millets across Eurasia: chronology and context of early records of the genera Panicum and Setaria from archaeological sites in the Old World. Veget Hist Archaeobot 17(Suppl 1):S5-S18

Hunt HV, Badakshi F, Romanova O et al (2014) Reticulate evolution in Panicum (Poaceae): the origin of tetraploid broomcorn millet, P. miliaceum. J Exp Bot 65:3165-3175

Kluyver TA, Charles M, Jones G, Rees M, Osborne CP (2013) Did greater burial depth increase the seed size of domesticated legumes? J Exp Bot 64:4101-4108

Liu L (2015) A long process towards agriculture in the middle Yellow River Valley, China: evidence from macro- and micro-botanical remains. J Indo-Pacific Archaeol 35:3-14

Liu L, Chen XC (2012) The Archaeology of China. Cambridge University Press, Cambridge

Liu XY, Hunt HV, Jones MK (2009) River valleys and foothills: Changing archaeological perceptions of North China's earliest farms. Antiquity 83(319):82-95

Liu L, Bestel S, Shi J, Song Y, Chen X (2013) Paleolithic human exploitation of plant foods during the last glacial maximum in North China. Proc Natl Acad Sci. 110:5380-5385

Liu XY, Zhao ZJ, Liu GX (2015) Xinglonggou. In: Barker G, Goucher $\mathrm{C}$ (eds) The Cambridge World History, vol 2. A world with agriculture, 12,000 BCE-500 CE. Cambridge University Press, Cambridge, pp 335-352

Liu XY, Motuzaite-Matuzeviciute G, Hunt HV (2019) From a fertile idea to a fertile arc: the origins of broomcorn millet 15 years on. In: Lightfoot E, Liu XY, Fuller DQ (eds) Far from the Hearth: Essays in Honour of Martin K. Jones, McDonald Institute of Archaeology, Cambridge, pp 155-164

Lu TLD (1998) Some Botanical Characteristics of Green Foxtail (Setaria viridis) and harvesting experiments on the Grass. Antiquity 72(278):902-907

Lu H, Zhang J, Liu K-B et al (2009) Earliest domestication of common millet (Panicum miliaceum) in East Asia extended to 10,000 years ago. Proc Natl Acad Sci 106:7367-7372

Maeda O, Lucas L, Silva F, Tanno KI, Fuller DQ (2016) Narrowing the harvest: Increasing sickle investment and the rise of domesticated cereal agriculture in the Fertile Crescent. Quat Sci Rev 145:226-237

Martin JH (1929) Proso or Hog Millet. US Department of Agriculture Farmers Bulletin 1162. USDA, Washington 
Matsuura A, Tsuji W, An P, Inanaga S, Murata K (2012) Effect of Pre- and Post-heading Water Deficit on Growth and Grain Yield of Four Millets. Plant Prod Sci 15(4):323-331

Motuzaite-Matuzeviciute G, Hunt HV, Jones MK (2012) Experimental approaches to understanding variation in grain size in Panicum miliaceum (broomcorn millet) and its relevance for interpreting archaeobotanical assemblages. Veget Hist Archaeobot 21:69-77

Nabhan G, de Wet JMJ (1984) Panicum sonorum in Sonoran Desert agriculture. Econ Bot 38:65-82

Palmer E (1871) Food products of the North American Indians. Report of the Commissioner of Agriculture 1870:404-428

Parker [Langloh Parker] K, (1905) The Euahlayi Tribe. Archibald Constable, London

Purugganan MD, Fuller DQ (2011) Archaeological data reveal slow rates of evolution during plant domestication. Evolution 65:171-183

Shelach-Lavi G (2015) The Archaeology of Early China. Cambridge University Press, Cambridge, From Prehistory to the Han Dynasty

Shelach-Lavi G, Teng MY (2013) Earlier Neolithic economic and social systems of the Liao River region, northeast China. In: Underhill AP (ed) A Companion to Chinese Archaeology. WileyBlackwell, Malden, pp 37-54

Shelach-Lavi G, Teng M, Goldsmith Y et al (2015) Report on the 2015 test excavations at the Jiajiagouxi site, Fumeng County, Liaoning Province. Bianjian Kaogu Yanjiu 25:53-69 ((in Chinese))

Shelach-Lavi G, Teng M, Goldsmith Y et al (2019) Sedentism and plant cultivation in northeast China emerged during affluent conditions. PLoS ONE 14:e0218751

Smith M (2013) The Archaeology of Australia's Deserts. Cambridge University Press, Cambridge

Song JX, Zhao ZJ, Fuller DQ (2013) The archaeobotanical significance of immature millet grains: An experimental case study of Chinese millet crop processing. Veget Hist Archaeobot 22:141-152

Stevens CJ, Fuller DQ (2017) The spread of agriculture in Eastern Asia: Archaeological bases for hypothetical farmer/language dispersals. Language Dynamics Change 7:152-186

Stevens C, Murphy C, Roberts R et al (2016) Between China and South Asia: A Middle Asian corridor of crop dispersal and agricultural innovation in the Bronze Age. Holocene 26:1541-1555

Sun B, Wagner M, Zhao ZJ et al (2014) Archaeological discovery and research at Bianbiandong early Neolithic cave site, Shandong, China. Quat Int 348:169-182

Tanno K-I, Willcox G (2012) Distinguishing wild and domestic wheat and barley spikelets from early Holocene sites in the Near East. Veget Hist Archaeobot 21:107-115

Teng M, Shelach-Lavi G, Su J et al (2015) Report on the 2015 test excavations at the Tachiyingzi site, Fumeng County, Liaoning Province. Bianjian Kaogu Yanjiu 25:1-40 ((in Chinese))

Walsh R (2017) Experiments on the effects of charring on Setaria italica (foxtail millet). Veget Hist Archaeobot 26:447-453
Wang C, Lu H, Zhang J, He K, Huan X (2016) Macro-Process of Past Plant Subsistence from the Upper Paleolithic to Middle Neolithic in China: A Quantitative Analysis of Multi-Archaeobotanical Data. PLoS ONE 11:e0148136

Wang C, Lu HY, Gu WF et al (2018) Temporal changes of mixed millet and rice agriculture in Neolithic-Bronze Age Central Plain, China: Archaeobotanical evidence from the Zhuzhai site. Holocene 28:738-754

Willcox G (2004) Measuring grain size and identifying Near Eastern cereal domestication: evidence from the Euphrates valley. $\mathbf{J}$ Archaeol Sci 31:145-150

Willcox G (2007) Agrarian change and the beginnings of cultivation in the Near East. In: Denham T, White P (eds) The Emergence of Agriculture: A Global View. Routledge, New York, pp 217-241

Wu WW, Wang XH, Wu XH, Jin GY, Tarasov PE (2014) The early Holocene archaeobotanical record from the Zhangmatun site situated at the northern edge of the Shandong Highlands, China. Quat Int 348:183-193

Xu Y, Liu M, Li C et al (2019) Domestication and spread of broomcorn millet (Panicum miliaceum L.) revealed by phylogeography of cultivated and weedy populations. Agronomy. 9:835. https://doi. org/10.3390/agronomy9120835

Yang XY, Wan Z, Perry L et al (2012) Early millet use in northern China. Proc Natl Acad Sci 109:3726-3730

Yang XY, Ma ZK, Li J, Yu JC, Stevens C, Zhuang YJ (2015) Comparing subsistence strategies in different landscapes of North China 10,000 years ago. Holocene 25:1957-1964

Yang Q, Li XQ, Zhou XY, Zhao KL, Sun N (2016) Quantitative reconstruction of summer precipitation using a mid-Holocene $\delta 13 \mathrm{C}$ common millet record from Guanzhong Basin, northern China. Clim Past 12:2229-2240

Zhao ZJ (2004) Addressing the origins of agriculture in North China based on the results of flotation from the Xinglonggou site. Dongya Kaogu 12:188-199 ((in Chinese))

Zhao ZJ (2011) New archaeobotanical data for the study of the origins of agriculture in China. Curr Anthropol 52(Suppl 4):S295-S306

Zhao ZJ (2014) The process of origin of agriculture in China: Archaeological evidence from flotation results. Quat Sci 34:73-84 ((in Chinese))

Zuloaga FO, Salariato DL, Scataglini A (2018) Molecular phylogeny of Panicum s. str. (Poaceae, Panicoideae, Paniceae) and insights into its biogeography and evolution. PLoS On 13:e0191529

Publisher's Note Springer Nature remains neutral with regard to jurisdictional claims in published maps and institutional affiliations. 